\title{
ASPECTS OF ANCIENT MITOCHONDRIAL DNA ANALYSIS IN DIFFERENT POPULATIONS FOR UNDERSTANDING HUMAN EVOLUTION
}

Nesheva DV ${ }^{1}$,

*Corresponding Author: Desislava V. Nesheva, Department of Medical Genetics, Medical Faculty, Medical University, 2 Zdrave str., fl. 6, 1431 Sofia, Bulgaria. Tel.: +35-92-917-2735; E-mail: desislava.nesheva@gmail.com

\begin{abstract}
The evolution of modern humans is a long and difficult process which started from their first appearance and continues to the present day. The study of the genetic origin of populations can help to determine population kinship and to better understand the gradual changes of the gene pool in space and time. Mitochondrial DNA (mtDNA) is a proper tool for the determination of the origin of populations due to its high evolutionary importance. Ancient mitochondrial DNA retrieved from museum specimens, archaeological finds and fossil remains can provide direct evidence for population origins and migration processes. Despite the problems with contaminations and authenticity of ancient mitochondrial DNA, there is a developed set of criteria and platforms for obtaining authentic ancient DNA. During the last two decades, the application of different methods and techniques for analysis of ancient mitochondrial DNA gave promising results. Still, the literature is relatively poor with information for the origin of human populations. Using comprehensive phylogeographic and population analyses we can observe the development and formation of the contemporary populations. The aim of this study was to shed light on human migratory processes and the formation of populations based on available ancient mtDNA data.

Keywords: Ancient DNA (aDNA); Evolution; Haplo-groups; Mitochondrial DNA (mtDNA); Population.
\end{abstract}

\footnotetext{
* Department of Medical Genetics, Medical Faculty, Medical University, Sofia, Bulgaria
}

\section{INTRODUCTION}

Mitochondrial DNA. Mitochondria are located out of the nucleus in cytoplasm of the cells. They play a central role in cell life and death. They have small genome, independent of the nuclear DNA-mitochondrial DNA (mtDNA). Mitochondrial DNAs are circular, double-stranded molecules, with high copy number, and a higher evolutionary importance compared to nuclear DNA. They have specific uniparental inheritance only from mothers to their child, which is useful for tracing matrilineal kinship in many generations [1-4].

Mitochondrial DNA is a proper tool for determination of the origin of different populations. It is an important object of study in different fields such as evolutionary anthropology, population genetics, medical genetics, genetic genealogy and forensic science $[1,5,6]$.

Mitochondrial DNAs are not involved in recombinant processes and their variants are due only to mutations. Mitochondrial DNA is characterized by a high mutation rate that allowed the sequential accumulation of neutral mutation-specific base replacements, especially transitions, which arose approximately at the same time, when people inhabited different regions all over the world. These mutations form groups of stable haplotypes and are known as haplogroups. Mitochondrial DNA haplogroups tend to be geographically restricted and they are used to genetically distinguish populations $[5,6]$.

Mitochondrial DNA Variability. The most variable part of mtDNA is the control region [dis- 
placement loop (D-loop)]. It is the biggest non coding part of mtDNA and plays a role in regulation and initiation of replication and transcription. The most polymorphic sequences in the control region are the hypervariable segment I and hypervariable segment II (HVS I and HVS II, respectively). They are objects of many studies and researches of the roots of populations and human evolution $[7,8]$.

The mtDNA variation data can be used for creating genealogical trees that contain information about the order of the evolutionary processes in space and time. The first mtDNA tree was created by Vigilant et al. [9], and the first five branching points of the mtDNA tree were from people living in sub-Saharan Africa. The understanding of the evolution of the mtDNA pedigree helped population geneticists to trace the ancestors of modern humans to their roots in Africa and their subsequent distribution in the world. It was determined that the Mitochondrial Eve lived in sub-Saharan Africa 200,000 years ago. As shown by fossils found in Israel, the earliest human invasions out of Africa started from the Kalahari Desert and the African rainforest 90,000 years ago. The successful migratory processes out of Africa has been proven by mtDNA data and is dated to 55,000 to 85,000 years ago. Researchers created the theoretical roads of migrations along the Nile and across the Sinai Peninsula spreading all over the world. Obtained data show that Australia and Asia were first to be inhabited [10], whereas Europe was initially colonized 45,000 years ago. Other important events in European prehistory are from 27,000 to 16,000 years ago at the Last Glacial Maximum forming the uninhabitable areas in Europe and between 9000 and 5000 years ago with the spread of the Neolithic culture in Europe [11].

Mitochondrial DNA Haplogroups. Today, the oldest mtDNA haplogroups are found in Africa. The first haplo-groups were L1, L2 and L3, and they gave rise to other macro-haplogroups and branches of the global phylogenetic tree during the migration waves from Africa all over the world. Haplogroup L3 is ancestral to macro-haplo-groups $\mathrm{M}$ and $\mathrm{N}$. They arose in northeast Africa and spread into Europe and Asia. Haplogroups H, I, J, N1b, T, U, V, W and X derived from haplogroup $\mathrm{N}$, and at present they comprise the majority of mtDNAs in Europe. The Asian haplogroups A, B, C, D, F and G derived from $\mathrm{M}$ and N. Haplogroups A, B, C and D are frequent among Native Americans [1].
Mitochondrial Gene Pool. The European mtDNA gene pool is quite homogeneous. The comparison of the sequences from Europe and other continents revealed that the genetic distances between European populations are much lower than between the populations from other continents. In the phylogenetic tree of several world populations, the European population forms a small cluster near Turkey and the Middle East. The formation of the modern European gene pool is probably complex, slow and a relatively recent process [12]. Recent studies show that over the past few millennia, populations living in northeastern Europe and Asia had close contacts. This is evidenced by different migration waves that crossed the Bosporus in both directions. The formation of the European populations was largely influenced by two large population expansions from the Middle East to the West (the initial colonization of the continent and the Neolithic expansion) [13].

The human mtDNA variations are being recorded by aligning mtDNA sequences to the revised Cambridge reference sequence (rCRS). The rCRS is the corrected version of the first fully sequenced mtDNA genome and belongs to haplogroup $\mathrm{H}$. The CRS was created in 1981 and revised in 1999 [14]. For the first time mtDNA was sequenced during the 1970s from a group under Dr. Fred Sanger at Cambridge University, Cambridge, Cambridgeshire, UK.

Ancient DNA. The development and improvement of technologies allowed the retrieval of DNA sequences from museum specimens, archaeological finds and fossil remains. This is the initial basis of ancient DNA (aDNA) research. Analyses and comparisons of ancient and modern mtDNA can provide evidence for the population origin and migration processes [15,16]. In 1983, Higuchi et al. [17] at Berkeley, CA, USA, first successfully extracted and sequenced ancient mtDNA from dried muscle, a 150-year-old museum specimen of the quagga, a zebra-like species. In 1985, Paabo studied Egyptian mummified material, the first human remains dating as far back as several thousand years [18]. In 1997, aDNA from Neanderthal specimens excavated from the Feldhofer Cave in Germany was successfully extracted [19].

Despite the doubt about the success of the investigations in the dawn of aDNA studies, the first results gave new directions in science such as the development of anthropogenetics and paleogenetics 
and increased their role in the evolutionary science.

In paleogenetic analyses, scientists sequenced the hypervariable fragments of mtDNA extracted from skeletal remains recovered from archaeological sites, they compared the results with literature data and classified mtDNAs into maternal lines according to the sequence polymorphism. This was a very useful approach and enabled the identification of the genealogy of individuals with a high level of authenticity. The genetic structure, origins, changes, migration routes of ancient people could certainly be more clearly understood. Most of the examinations for tracing ancient human movements and obtaining dates for genetic prehistory are now routinely performed. Their main idea is to create chronology linking living contemporary humans with their ancestors. The examinations of ancient populations in the last 10 years strongly imply the major role of ancient mtDNA studies in the determination of features of the prehistoric migrations and demographic expansions [20,21].

Authenticity and Contamination. The main problem with authenticity of aDNA is contamination with exogenous, mostly contemporary DNA; postmortem damages; errors during work in the multiple independent amplification and sequencing processes; degradation and low copy number of partly preserved mtDNA. These problems are sufficient reason to create criteria for working with old samples. Such criteria were suggested by Cooper and Poinar [22]. These criteria are useful for establishing the methods and techniques for working with these kinds of samples. The implementation of these strategies will help to have effective and successful results from ancient mtDNA [22]. On the other hand, the Nine Criteria will elevate the chances for authentic results in ancient mtDNA extraction and sequencing. The Nine Criteria include repeatability of experiments from two separate extracts, necessary to prove previous results. Posterior controls of the samples are performed to avoid the presence of traces or sequences that can be from the excavation team, curating staff, or laboratory personnel rather than mtDNA lineages that would be expected. In other words, posterior controls are searching for the presence of mosaic or abnormal structure that can be evidence of contamination. When the combination from different sequenced fragments of aDNA are not close to any point in the phylogeny or have an un- usual combinations of mutations, they are considered to be a result of postmortem changes and phantom mutations. The scientists noted that checking work at every step will help to provide and confirm the authenticity of aDNA [23,24]. Another important point is working in a high level of sterile conditions. The monitoring of contamination should start during the excavation of the remains. The results from the sequencing of the samples should be compared with the sequences of all the people who are performing the analyses. The ancient and modern DNA laboratories should be separate, and the working surfaces should be UV irradiated [25]. Researchers planning to perform aDNA studies have to be able to follow all necessary criteria for aDNA work.

There is a theory for the discrimination of contaminant from endogenous sequences of mtDNA, according to which contaminant sequences are longer than the endogenous one, because in ancient samples DNA is degraded from long time preservation. The length of the obtained sequences can be directly observed using shotgun sequencing of mtDNA. On the basis of this theory, the scientists found that up to $80.0 \%$ of the longest sequences of the Neanderthal were modern human contaminations. Further analyses have shown that endogenous and contaminant sequences presented different length distributions and the size reduction depends upon different factors such as age of the samples and level of contamination. The theory is not useful in some cases and especially in a particular set of sequences because there is wide overlapping of the length distributions in different samples. But even this, the scientists concluded that these criteria can be applied for measuring the authenticity with increased confidence for all ancient high-throughput sequencing data sets $[25,26]$.

The retrieval of mtDNA from ancient human specimens is not always successful owing to DNA deterioration and contamination. Usually only short DNA fragments can be retrieved from these ancient specimens. Even though ancient DNA provided the limited amount of data in the past, it is the main resource for direct information about our ancient ancestors. The analyses of ancient samples can provide new perspectives on human history, but the problem with degradation and contamination in long-term preserved specimens still makes analyses very difficult. This is due to the technical difficulties with extraction, amplification and sequencing of ancient 
mtDNA. The scientists tried to improve different methods and techniques for working with ancient mtDNA, such as polymerase chain reaction (PCR) with specifically constructed primers for short overlapping fragments covering large-size sequences containing haplogroup-diagnostic mutations, cloning and sequencing. There are still no absolutely perfect techniques for obtaining authentic aDNA, but researchers are working on finding them [15].

Materials and Methods for Ancient Mitochondrial Phylogenetic Analyses. The main materials that can be used for extracting ancient mtDNA are usually dry hard remains: roots of teeth or pieces of femur. They are the appropriate source of aDNA, because they preserve DNA for a long period of time. There are several well established protocols for extracting, amplification and sequencing of ancient mtDNA (especially HVS I and HVS II). Extraction of mtDNA from bone powders usually follows the protocols and controls for sterility, as phenol-chloroform or silica-based protocols are usually applied $[27,28]$. Several steps of amplification of fragments of mtDNA are necessary because DNA is fragmented due to long-term preservation. The fragments are overlapped, which allows the covering of the whole mtDNA genome or the HVS I and HVS II regions. In the next step of the protocol, the fragments are cloned by using specific competent cells (E. coli) that allows control of the fragments' quality and the screening of the correctly inserted clones [29]. The Sanger et al. [30] method is primarily used for the sequencing. In the last 5 years, there have been attempts to apply next generation sequencing as a method for analysis of ancient samples. These attempts show that next generation sequencing is suitable for aDNA research [31].

Neanderthals and Anatomically Modern Humans. Ancient DNA studies demonstrated their potential to help us to understand the macro-evolutionary history, particularly when it came to clarify the relationships between existing and extinct species. Working with ancient mtDNA can prove or reject the theory that Neanderthals and anatomically modern humans contributed in varying degrees to the modern human gene pool. Some studies of Nean-derthals and early humans show that they did not intermingle. Other studies show different results. Thus, the sequencing of HVRI of 23,000- and 25,000-year-old bones from ancient people reveal that they are not so different from contemporary people but they differ from Nean-derthals. This conception is in the basis of the multire-gional hypothesis of modern human origins [32]. There are studies showing that the evolutionary history of Neander-thals and modern humans is characterized by similar demographics parameters $[33,34]$. These surveys try to prove the hypothesis for interbreeding between Neanderthals and anatomically modern humans. They found changes in the morphology of late Neanderthals and observed some features in anatomically modern humans that are influenced from Neanderthals. The examination of the mandible from Riparo Mezzena, a Middle Paleolithic rock shelter in the Monti Lessini, Verona, Italy, showed that it was anatomically typical of modern humans but genetically and morphologically typical of late Neanderthals [35-37]. The study confirms that, this change in the morphology of the mandibular chin of Mezzena and other late Neanderthals, could be the result of a small degree of interbreeding with anatomically modern humans or genetic admixtures between Homo sapiens and Homo neanderthalensis [35,38]. This examination will help for better understanding the transition between these to human groups. The changes in the morphology in late Neanderthals lend support to the hypothesis of continuity with anatomically modern humans or interbreeding with them.

\section{Changes During the Neolithic and Formation} of the European Gene Pool. In a study of archaeological and paleoecological data of ancient samples (in 1995) it was shown that genetic differences observed in Basques are compatible with migration during the last glacial period around 18,000 years. After the spread of modern humans in Europe, high levels of migration, particularly in the Neolithic period, probably contributed to the homogenization of the gene pool in Europe $[39,40]$. About 11,000 years ago there was replacement of the hunting-and-gathering lifestyle in the Near East with agriculture. Agriculture spread into Europe about 7500 years ago and it reached from Hungary and Slovakia to Ukraine in the east and to France in the west. There is an on-going archeological, anthropological and population genetic debate whether the spread of farming involved large farmers migrations, i.e., demic diffusion or if it was due to cultural diffusion. A study comparing ancient DNA from the early farmers and hunter-gatherers shows that farmers were genetically so distinct from hunter-gatherers that they could not be geneti- 
cally related [41]. The comparison of ancient mtDNA with mtDNA from contemporary Europeans revealed that there was little genetic similarity between the hunter-gatherers and modern Europeans, suggesting that the modern Europeans descended from the incoming farmers, not from the native populations. The study suggested that additional waves of migration and later admixture with hunter-gatherers also shaped the modern European gene pool. From the above mentioned, we concluded that there are still unanswered questions about these populations that can be solved in future investigations [42].

Another independent research group interested in Neolithic revolution recently worked with mtDNA from skeletons of pre Neolithic hunter-gatherers as well as early Neolithic farmers and compared the results with modern data. They support the model of demic diffusion [43]. Researchers identified mtDNA haplogroups that are typical for early farmers (haplogroup H) and hunter-gatherers (haplogroup U). The analyses of mtDNAs typical for hunters and gatherers showed population expansion between 15,000 and 10,000 years ago and corresponded to an analogous population increase approximately 9000 years ago, characterized with mtDNAs typical for early farmers. The spread of agriculture in Europe pushed the expansion of farming populations into Europe followed by the admixture with resident hunter-gatherers. This was confirmed with results from analyses of mtDNA belonging to haplo-group $\mathrm{H}$, which are indicative for population expansions and spread of the farming culture. The mtDNAs belonging to haplogroup $\mathrm{U}$ showed that the earlier hunter-gatherers adopted farming practices and admixed with the immigrant farming populations [44].

Development of Central Europe. In another study, scientists tried to locate the origins and trace potential dis-persal routes of populations which had lived in Central Europe by using comprehensive phylogeographic and population genetic analyses. They described the Neolithic mtDNA sequence diversity and the geographical affinities of the early farmers using a large database of extant Western Eurasian and European populations. This was the first detailed genetic analysis of the earliest Neolithic culture in Central Europe, which identified Neolithic haplotypes that left clear traces in the modern populations. The results confirmed that the demographic events that had great influence in Europe occurred after the early Neo- lithic. These early populations show unique genetic features and they have an affinity with modern-day populations from the Near East and Anatolia $[45,46]$.

These data from Central Europe were compared with the results from the analysis of mtDNA diversity in hunter-gatherers and first farmers from Northern Spain. The analyzed samples were dated to the Paleolithic and Early Neolithic. The results from the analysis do not support the demic and cultural diffusion models, but they support a random dispersion model for Neolithic farmers in the Mediterranean region. This model points to a differentiation in the various geographic regions due to the transport of different, small Neolithic groups from the Near Eastern gene pool [47].

Research of Past Populations and Their Influence on Contemporary Ones: Scandinavian Populations. A research from 2010 concerning Scandinavian populations was focused on ancient individuals from different Danish regions dating from the Mesolithic to the Medieval Age. The results show that the ancient mtDNA diversity varies in the different regions. The ancient Danish populations are not so different from the present-day populations and other modern Scandinavians, with the exception of haplogroup I, which is significantly more frequent among the ancient Danes than among modern Danes and Scandinavians. The Neolithic and Bronze Age Danish samples had haplogroups associated with the Mesolithic populations of Central and Northern Europe (U4 and U5a). These findings show that Southern Scandinavian populations do not belong to more diverse haplogroups, which dominated in hunter-gatherer populations during the Neolithic era [48]. Investigations made by Helgason et al. $[49,50]$ in the period from 2003 to 2009, of the early medieval Icelandic skeletal remains dated from $1000 \mathrm{AD}$, show that their sequences are more close to the sequences from contemporary inhabitants of Scotland, Ireland, and Scandinavia than to those from the modern Icelandic population. The scientists thought that this could be due to the fact that the gene pool of this small Icelandic population was more affected by genetic drift (during the last 1100 years) than the mtDNA pools of the larger European populations [49,50].

Guanches in the Canary Islands. Small-scale and local anthropogenetic researches can help to understand the history and to detect the ancestors of certain populations. Such analyses are those of 
Rando et al. [51] and Maca-Mayer et al. ]52[, involving approximately 1000-year-old aboriginal remains from the Canary Islands. These scientists were studying the origins of contemporary population of the Islands, based on historical information from the prehistoric colonization of the Canary Islands by the Guanches to the Europeans' conquest of the Archipelago. They determined that the Guanches carried U6b1 mtDNA lineages that are found in the present day Canary Islands population, but are not found in Northwest Africans. On other hand, phylogenetical $\mathrm{U} 6 \mathrm{~b}$ is not present in the native Canary Islanders. There is a high genetic and ethnic diversity found in the Guanches. The comparisons with other populations related to the Guanches show that despite the series of population changes, the aboriginal mtDNA lineages played a big role in the formation of the Canary Islanders' gene pool. They concluded that the Ber-bers are the most probable descendants of the Guanches, although important human movements did reshape Northwest Africa after the migratory wave to the Canary Islands [51,52].

Native Americans. Searching the roots of modern Native Americans, Kaestle and Smith in 2001 [53] determined the frequencies of five different haplogroups among the ancient individuals from Western Nevada dating approximately $350-9200$ years before the present. The Numic speakers (current inhabitants of the Great Basin, Nevada, North America), are recent immigrants into the area who replaced the previous inhabitants. There is a significant genetic discontinuity between the ancient inhabitants and the modern Numic speakers that supports the hypothesis for the Recent Numic Expansion. There is regional variation over time and it correlates with population movements hypothesized from linguistics and archaeological studies. It is also suggested that genetic drift has not influenced the haplogroup frequency distributions [53].

Southeast Asia. Investigation of the genetic relationships and history among two neighboring populations of early agricultural communities in northeastern Thailand from the fourth millennium before the present day and comparing with various ethnic modern populations of East and Southeast Asia, shows that the two ancient samples were most closely related to each other, and closely related to the part of modern populations living near the archaeological sites. It was suggested that the ge- netic continuum may have persisted since prehistoric times. Formation of ethnic populations was complicated culturally and genetically. It was important to know the contemporary ethnic populations of this geographic area, direct genetic descendants of their ethnic and linguistic predecessors, in order to trace the expansion of the ethnic populations. For the first time, the analysis of aDNA from these archaeological sites extends the knowledge about the complex demographic history and genetic relations of the known ethnic populations of Southeast Asia [54,55].

Terra Cotta Warriors in China. There is an interesting analysis from Xu et al. in 2008 [56] performed with bone remains, which were supposed to be from workers building the mausoleum for the First Emperor of China, that were excavated near the Terra Cotta Warriors and dated 2200 years ago. The geneticists investigated mitochondrial lineages of these bone specimens to confirm the hypothesis that mausoleum-building workers were brought in from various geographic areas. They saw that the slave workers of the Qin Dynasty were extremely genetically diverse. They concluded that the workers were an admixture and it is difficult to determine genetic continuity with contemporary Chinese populations. It is necessary to do more studies in this field [56].

Hungarian Populations. During 2007, the Hungarian team led by Tomory et al. [57], examined ancient samples dating back to the 10th-11th centuries and compared them with contemporary Hungarians and different European and Asian populations. It was found that there are genetic differences and no genetic continuity between ancient and modern Hungarians. The genetic affinity among ancient Hungarians and Asian populations is small and the genetic affinity among ancient Hungarians and Western Eurasian populations is large. The modern Hungarian populations are typically European. From the final results, the conclusion was that Hungarians are genetically influenced from Slavic, Balkan and Western Eurasian populations. The Seklers, Hungarian-speaking population in Transylvania, have more genetic influence from Eastern and Southern Europeans [57].

Ancient Australians. Adcock et al. in 2001 [58] made a reconstruction of ancient mtDNA from the late Pleistocene and early Holocene (from 60,000 to 8000 years ago) eras in Australia. The results indicated that anatomically modern humans were present in Australia before the complete fixation of the mtDNA 
lineages now found in all living people. When comparing the ancient and modern Australians, scientist found that the anatomically modern humans were among those that were replaced and that part of the replacement occurred in Australia during its colonization. Other interesting findings were that anatomical features and the mtDNA of particular individuals may have had different evolutionary pathways. Some nuclear gene lineages have different genealogical and geographical characteristics from mtDNA. The scientists found that the most divergent mtDNA lineage from an anatomically modern human was from an Australian individual. These findings present other possible models for the demographic and evolutionary history of our species on the basis of described deep lineages in Africa and even deeper lineages in Australia [58].

Yakuts Populations in Siberia. Tracing the origins of Yakuts, an enigmatic ethnic group living in $\mathrm{Si}-$ beria, Crubézy et al. in 2010 [59], extracted mtDNA from frozen bodies dated between the 15th and 19th centuries. They used a combination of ethnological and linguistic criteria as well as population genetic studies to find their roots. The Yakuts contrast from other populations in Siberia in different aspects such as funeral rituals and lifestyles, they are the most remarkable case of expansion into North Siberia. The comparison with contemporary populations provided evidence of microevolution of the Yakut population. This can be observed in few regions in the world and it is an interesting scientific finding [59]. The earlier researches for investigating the origin and evolution of the Yakut populations performed on frozen bodies dated 300-600 years ago and older ancient samples made comparisons with Eurasian modern individuals and they provided more comprehensive insights of the Yakut populations history [60].

Native Britons. British history and genetic diversity are very interesting, and in order to understand them, Topf et al. [61] performed an analysis of ancient mtDNA from remains dated between 300 to 1000 years $\mathrm{AD}$, and compared the results with data for contemporary Britons, Europeans and Middle Eastern populations. The analysis showed that there is loss of diversity over the last millennium. The ancient samples have greater genetic diversity than modern populations. The observed pattern is probably due to stochastic processes that lead to the increasing representation of the ancient haplotypes in modern populations [61]. Similarly, the gene pool of the Icelandic population contains evidence of drift distorting haplotype frequencies as the contribution of ancestral lines is highly contorted and necessitates further research to estimate relative importance, because drift or selection, or both, can be involved [49,61].

Peruvian Populations. Interesting objects of anthro-pogenetic researches are the Peruvian populations who lived near Machu Picchu in the Andes in Peru. They were investigated in 2006 by the team of Shinoda et al. [62]. The examined populations were close to populations in the Peruvian and Bolivian highlands and far from pre Hispanic individuals of the north coast of Peru. There is a suggestion that late pre Hispanic individuals and modern Andean highlanders have strong relations and they were a mixed group of natives from various coastal and highland regions relocated by the Inca state. The final results showed that populations who have lived near to Machu Picchu are indigenous highlanders who provided supportive roles for the Machu Picchu region [62].

\section{CONCLUSIONS}

In recent years, anthropologists and geneticists joined to create a map of possible prehistoric human migration routes and time scales for a detailed reconstruction of prehistoric and historic events. They used ancient and modern data and combined the information to create a picture of our history since the appearance of modern humans 200,000 years ago in East Africa.

There are still only small amounts of data for the genetic makeup of the ancient populations. The available data are scarce and there is a necessity of more research in this field in order to fill the gap of the European map of ancient populations who lived in this land at different periods of time.

By combining and comparing present and future results, we can create a map of ancient populations and their relationships from the first settled groups to their contemporaries in the present day countries. The process of creating the full picture of human evolution is complicated and needs further analyses in places from which aDNA has not yet been surveyed.

The structure and evolution of the mtDNA gene pool of contemporary Bulgarians has been previously analyzed in a large sample comprising 855 individuals [63]. In order to further clarify and directly observe 
the gradual changes of the matrilineal composition of Bulgarians, we will perform phylogenetic analyses of ancient DNA retrieved from human remains found in different places of the country and dating to different periods of the Bulgarian past. The obtained data will contribute not only to the better understanding of the Bulgarian genetic past, but it will also shed new light on the European genetic evolution.

\section{REFERENCES}

1. Shriver MD, Kittles RA. Genetic ancestry and the search for personalized genetic histories. Nat Rev Genet. 2004; 5(8): 611-618.

2. Suissa S, Wang Z, Poole J, Wittkopp S, Feder, Shutt TE, et al. Ancient mtDNA genetic variants modulate mtDNA transcription and replication. PLoS Genet. 2009; 5(5): e1000474.

3. Moreno-Loshuertos R, Acin-Perez R, Fernandez-Silva P, Movilla N, Perez-Martoz A, Rodriguez de Cordoba $\mathrm{S}$, et al. Differences in reactive oxygen species production explain the phenotypes associated with common mouse mitochondrial DNA variants. Nat Genet. 2006; 38(11): 1261-1268.

4. Kazuno AA, Manukata K, Nagai T, Shimozono $\mathrm{S}$, Tanaka $\mathrm{M}$, Yoneda $\mathrm{M}$, et al. Identification of mitochondrial DNA polymorphisms that alter mitochondrial matrix $\mathrm{pH}$ and intracellular calcium dynamics. PLoS Genet. 2006; 2(8): e128.

5. Anderson S, Bankier AT, Barrell BG, de Bruin $\mathrm{MH}$, Coulson AR, Drouin J, et al. Sequence and organization of the human mitochondrial genome. Nature. 1981; 290(5806): 457-465.

6. Pakendorf B, Stoneking M. Mitochondrial DNA and human evolution. Annu Rev Genomics Hum Genet. 2005; 6: 165-183.

7. Horai S, Hayasaka K, Kondo R, Tsugane K, Takahata N. Recent African origin of modern humans revealed by complete sequences of hominoid mitochondrial DNAs. Proc Natl Acad Sci USA. 1995; 92(2): 532-536.

8. Tully LA, Parsons TJ, Steighner RJ, Holland MM, Marino MA, Prenger VL. A sensitive denaturing gradient-gel electrophoresis assay reveals a high frequency of het-eroplasmy in hypervariable region 1 of the human mtDNA control region. Am J Hum Genet. 2000; 67(2): 432-443.
9. Vigilant L, Stone king M, Harpending H, Hawkes K, Wilson AC. African populations and the evolution of human mitochondrial DNA. Science. 1991; 253(5027): 1503-1507.

10. Forster P, Matsumura S. Evolution. Did early humans go north or south? Science. 2005; 308(5724): 965-966.

11. Salas A, Richards M, de la Fe T, Lares MV, Sobrino B, Sanchez-Diz P, et al. The making of the African mtDNA landscape. Am J Hum Genet. 2002; 71(5): 1082-1111.

12. Comas D, Calafell F, Mateu E, Perez-Sezaun A, Bosch E, Bertranpetit J. Mitochondrial DNA variation and the origin of the Europeans. Hum Genet. 1997; 99(4): 443-449.

13. Calafell F, Underhill P, Tolu A, Angelicheva D, Kalaydjieva L. From Asia to Europe: Mitochondrial DNA sequence variability in Bulgarians and Turks. Ann Hum Genet. 1996; 60(Pt 1): 35-49.

14. Andrews RM, Kubacka I, Chinnery PF, Lightow-lers RN, Turnbull, Howell N. Reanalysis and revision of the Cambridge reference sequence for human mitochondrial DNA. Nat Genet. 1999; 23(2): 147.

15. Yonggang Y, Yaping Z. Pitfalls in the analysis of ancient human mtDNA. Chinese Sci Bull. 2003; 48(8): 826-830.

16. Yao YG, Zhang YP. Mitochondrial DNA and human evolution (in Chinese). Zool Res. 2000; 21(4): 392-406.

17. Higuchi R, Bowman B, Freiberger M, Ryder $\mathrm{OA}$, Wilson AC. DNA sequences from the quagga, an extinct member of the horse family. Nature. 1984; 312(5991): 282-284.

18. Paabo S. Molecular cloning of ancient Egyptian mummy DNA. Nature. 1985; 314(6012): 644-645.

19. Krings M, Stone A, Schlitz RW, Krainitzki H, Stone king M, Paabo S. Neanderthal DNA sequences and the origin of modern humans. Cell. 1997; 90(1): 19-30.

20. Adachi N, Umetsu K, Takigawa W, Sakauea K. Phylogenetic analysis of the human ancient mitochondrial DNA. J Archaeol Sci. 2004; 31(10): 1339-1348.

21. Forster P. Ice Ages and the mitochondrial DNA chronology of human dispersals: A review. Philos Trans R Soc Lond B Biol Sci. 2004; 359(1442): 255-264 (discussion: 264). 
22. Cooper A, Poinar HN. Ancient DNA: Do it right or not at all. Science. 2000; 289(5482): 1139.

23. Kolman CJ, Tuross N. Ancient DNA analysis of human populations. Am J Phys Anthropol. 2000; 111(1): 5-23.

24. Bandelt HJ. Mosaics of ancient mitochondrial DNA: positive indicators of nonauthenticity. Eur J Hum Genet. 2005; 13(10): 1106-1112.

25. Garcia-Garcera M, Gigli E, Sanchez-Quinto F, Ramirez O, Calafell F, Civit S, et al. Fragmentation of contaminant and endogenous DNA in ancient samples determined by shotgun sequencing; prospects for human palaeogenomics. PLoS One. 2011; 6(8): e24161.

26. Wall JD, Kim SK. Inconsistencies in Neanderthal genomic DNA sequences. PLoS Genet. 2007; 3(10): 1862-1866.

27. Pilli E, Modi A, Serpico C Chilli A, Lancioni H, Lippi B, et al. Monitoring DNA contamination in handled vs. directly excavated ancient human skeletal remains. PLoS One. 2013; 8(1): e52524.

28. Richards M, Smalley K, Sykes B, Hedges R. Archaeology and genetics: Analyzing DNA from skeletal remains. World Archaeol. 1993; 25(1): 18-28.

29. Caramelli D, Milani L, Vai S, Modi A, Pecchioli E, Girard M, et al. A 28,000 years old Cro-Magnon mtDNA sequence differs from all potentially contaminating modern sequences. PLoS One. 2008; 3(7): e2700.

30. Sanger F, Nicklen S, Coulson AR. DNA sequencing with chain-terminating inhibitors. Proc Natl Acad Sci USA. 1977; 74(12): 5463-5467.

31. Knapp M, Hofreiter M. Next generation sequencing of ancient DNA: Requirements, strategies and perspectives. Genes (Basel). 2010; 1(2): 227-243.

32. Wolpoff MH, Caspari R. Race and Human Evolution: A Fatal Attraction. New York, NY: Westview Press, Simon \& Schuster. 1997: 11-18.

33. Caramelli D, Laluela-Fox C, Vernesi C, Lari M, Caroli A, Mallegni F, et al. Evidence for a genetic discontinuity between Neanderthals and 24,000-year-old anatomically modern Europeans. Proc Natl Acad Sci USA. 2003; 100(11): 6593-6597.

34. Lalueza-Fox C, Sampietro ML, Caramelli D, Puder Y, Lari M, Calafell F, et al. Neanderthal evolutionary genetics: mitochondrial DNA data from the Iberian Peninsula. Mol Biol Evol. 2005; 22(4): 1077-1081

35. Condemi S, Mounier A, Giunti P, Lari M, Caramelli D, Longo L. Possible interbreeding in late Italian Neanderthals? New data from the Mezzena jaw (Monti Lessini, Verona, Italy). PLoS One. 2013; 8(3): e59781.

36. Smith FH, Falsetto AB, Donnelly SM. Modern human origins. Yearbook Phys Anthropol. 1989; 32: 35-68.

37. Frayer D. Evolution at the European edge: Neanderthal and Upper Paleolithic relationships. Préhistoire Européenne. 1992; 2: 9-69.

38. Eriksson A, Manica A. Effect of ancient population structure on the degree of polymorphism shared between modern human populations and ancient hominins. Proc Natl Acad Sci USA. 2012; 109(35): 13956-13960.

39. Bertranpetit J, Sala J, Calafell F, Underhill PA, Moral P, Comas D. Human mitochondrial DNA variation and the origin of Basques. Ann Hum Genet. 1995; 59(Pt 1): 63-81.

40. Cavalli-Sforza LL, Menozzi P, Piazza A. Demic expansions and human evolution. Science. 1993; 259(5095): 639-646.

41. Bramanti B, Thomas MG, Haak W, Unterlaender M, Jores $\mathrm{P}$, Tambets $\mathrm{K}$, et al. Genetic discontinuity between local hunter-gatherers and central Europe's first farmers. Science. 2009; 326(5949): 137-140.

42. Balter M. Archaeology. Ancient DNA says Europe's first farmers came from afar. Science. 2009; 325(5945): 1189.

43. Sampietro ML, Lao O, Caramelli D, Lari M, Pou R, Marti M, et al. Palaeogenetic evidence supports a dual model of Neolithic spreading into Europe. Proc Biol Sci. 2007; 274(1622): 2161-2167.

44. Fu Q, Rudan P, Paabo S, Krause J. Complete mitochondrial genomes reveal neolithic expansion into Europe. PLoS One. 2012; 7(3): e32473.

45. Richards M. The neolithic invasion of Europe. Annu Rev Anthropol. 2003; 32: 135-162.

46. Haak W, Balanovsky O, Sanchez JJ, Kosher $\mathrm{S}$, Zaporoshchenko V, Adler CJ, et al. Ancient DNA from European early neolithic farmers 
reveals their near eastern affinities. PLoS Biol. 2010; 8(11): e1000536.

47. Hervella M, Izagirre $\mathrm{N}$, Alonso $\mathrm{S}$, Fregel $\mathrm{R}$, Alonso A, Cabrera VM, et al. Ancient DNA from hunter-gatherer and farmer groups from Northern Spain supports a random dispersion model for the Neolithic expansion into Europe. PLoS One. 2012; 7(4): e34417.

48. Melchior L, Lynnerup N, Siegismund HR, Kivisild T, Dissing J. Genetic diversity among ancient Nordic populations. PLoS One, 2010. 5(7): p. e11898.

49. Helgason A, Hrafnkelsson B, Gulcher JR, Ward R, Stefansson K. A populationwide coalescent analysis of Icelandic matrilineal and patrilineal genealogies: Evidence for a faster evolutionary rate of mtDNA lineages than $\mathrm{Y}$ chromosomes. Am J Hum Genet. 2003; 72(6): 1370-1388.

50. Helgason A, Lalueza-Fox C, Ghosh S, Sigurethar-dottir S, Sampietro ML, Gigli E, et al. Sequences from first settlers reveal rapid evolution in Icelandic mtDNA pool. PLoS Genet. 2009; 5(1): e1000343.

51. Rando JC, Cabrera VM, Larruga JM, Hernandez M, Gonzalez AM, Pinto F, et al. Phylogeographic patterns of $\mathrm{mtDNA}$ reflecting the colonization of the Canary Islands. Ann Hum Genet. 1999; 63(Pt 5): 413-428.

52. Maca-Meyer N, Array M, Rando JC, Flores C, Gonzalez AM, Cabrera VM, et al. Ancient mtDNA analysis and the origin of the Guanches. Eur J Hum Genet. 2004; 12(2): 155-162.

53. Kaestle FA, Smith DG. Ancient mitochondrial DNA evidence for prehistoric population movement: The Numic expansion. Am J Phys Anthropol. 2001; 115(1): 1-12.

54. Jin L, Seielstad M, Xiao C. Genetic, linguistic and archaeological perspectives on human diversity in Southeast Asia. In: Oxnard CE, Ed. Recent Advances in Human Biology. New Jersey, NJ: World Scientific. 2001: 17-34.
55. Lertrit P, Poolsuwan S, Thosarat R, Sanpachudayan T, Boonyarit H, Chinpaisal C, et al. Genetic history of Southeast Asian populations as revealed by ancient and modern human mitochondrial DNA analysis. Am J Phys Anthropol. 2008; 137(4): 425-440.

56. Xu Z, Zhang F, Xu B, Tan J, Li S, Li C, et al. Mitochondrial DNA evidence for a diversified origin of workers building First Emperor of China. PLoS One. 2008; 3(10): e3275.

57. Tomory G, Csany B, Bogacsi-Szabo E, Kalmar T, Czibula A, Csosz A, et al. Comparison of maternal lineage and biogeographic analyses of ancient and modern Hungarian populations. Am J Phys Anthropol. 2007; 134(3): 354-368.

58. Adcock GJ, Dennis ES, Osteal S, Huntley GA, Germain LS, Peacock WJ, et al. Mitochondrial DNA sequences in ancient Australians: implications for modern human origins. Proc Natl Acad Sci USA. 2001; 98(2): 537-542.

59. Crubézy E, Amory S, Geyser C, Bouakaze C, Bodner M, Gilbert M, et al. Human evolution in Siberia: from frozen bodies to ancient DNA. BMC Evol Biol. 2010; 10: 25.

60. Ricaut FX, Geyser-Tracqui C, Bland in P, Crubézy E, Ludes B. Mitochondrial DNA analysis of ancient Yakut skeletons. International Congress Series 1261. 2004: 392-394.

61. Topf AL, Gilbert MT, Fleischer RC, Hoelzel AR. Ancient human mtDNA genotypes from England reveal lost variation over the last millennium. Biol Lett. 2007; 3(5): 550-553.

62. Shinoda K, Adachi N, Guillen S, Shimada I. Mitochondrial DNA analysis of ancient Peruvian highlanders. Am J Phys Anthropol. 2006; 131(1): 98-107.

63. Karachanak S, Carissa V, Nesheva D, Olivieri A, Pala M, Hooshiar Kashani B, et al. Bulgarians vs the other European populations: a mitochondrial DNA perspective. Int J Legal Med. 2012; 126(4): 497-503. 